\title{
Do Audio-Visual Aids Help in Improving Oral Hygiene in Orthodontic Patients?
}

\author{
Arya S. Prasad ${ }^{1}$, Arvind Sivakumar ${ }^{2}$ \\ 1,2 Department of Orthodontics and Dentofacial Orthopaedics, Saveetha Dental \\ College and Hospitals, Saveetha Institute of Medical and Technical Sciences \\ (SIMATS), Saveetha University, Chennai, Tamilnadu, India.
}

\section{ABSTRACT}

\section{BACKGROUND}

Oral hygiene maintenance is a crucial factor for successful orthodontic therapy. Oral hygiene compliance is a must to maintain better oral hygiene and plaque control in orthodontic patients. To get good oral hygiene compliance the information has to reach the patients in a proper way. The purpose of this study was to determine whether audio - visual aids help in improving oral hygiene status in orthodontic patients.

\section{METHODS}

A prospective randomized control trial study was done on 30 subjects, who underwent fixed orthodontic appliances selected from the out-patient department of Department of Orthodontics and Dentofacial Orthopaedics, Saveetha Dental College and Hospitals, (SIMATs), Chennai. They were divided randomly into two groups based on a computer - generated randomization chart: group 1 - experimental group (audio - visual aids group), group 2 - control group (verbal instruction) respectively. Group 1 subjects received oral hygiene instruction through videotape instructions and group 2 received verbal and written instructions.

\section{RESULTS}

The results were assessed with respect to plaque index scores of both groups. A parametric intragroup comparison (paired ' $t$ ' test) was done to compare the before and after plaque score of each group and student independent sample ' $t$ ' test to compare both groups. The plaque score for the verbal group was found to be $0.666+$ / - 0.417 and for the audio - visual group it was $1.211+/-0.261$. A statistically significant $\mathrm{P}$ - value $(<0.05)$ was found between the groups.

\section{CONCLUSIONS}

Patients who were given instructions through audio - visual aids had better improvement in plaque scores than patients who were given instructions verbally.

\section{KEY WORDS}

Audio - Visual Aids, Dental Plaque Index, Oral Hygiene, Oral Hygiene Index, Orthodontic Appliance
Corresponding Author:

Dr. Arya S. Prasad,

Department of Orthodontics and

Dentofacial Orthopaedics,

162, Poonamallee High Road,

Velappanchavadi, Chennai,

Tamil Nadu - 600077, India.

E-mail: aryasprasad7@gmail.com

DOI: $10.14260 / j e m d s / 2021 / 346$

How to Cite This Article:

Prasad AS, Sivakumar A. Do audio-visual aids help in improving oral hygiene in orthodontic patients? J Evolution Med Dent Sci 2021;10(22):1667-1671, DOI: $10.14260 / \mathrm{jemds} / 2021 / 346$

Submission 06-07-2020,

Peer Review 01-04-2021

Acceptance 07-04-2021,

Published 31-05-2021.

Copyright (C) 2021 Arya S. Prasad et al. This is an open access article distributed under Creative Commons Attribution License [Attribution 4.0 International (CC BY 4.0)] 


\section{BACKGROUND}

Oral hygiene is a critical factor controlled by the patient, which can affect the quality and outcome of orthodontic treatment. ${ }^{1}$ Patients with fixed appliances are always at a greater risk of developing white spot lesions, gingivitis, and are more prone to caries. ${ }^{2}$ Poor oral hygiene can not only increase the treatment duration but also it can affect the treatment outcome.3,4 A previous study has shown that in patients with fixed orthodontic appliances, there was a significant increase in the quantity of plaque as these appliances make plaque removal difficult especially between the gingival margins and brackets. ${ }^{5}$ So oral hygiene measures have to be even better and more effective to reduce the amount of plaque in these patients. Oral hygiene habits tend to vary in different kinds of the population that too can influence the health of patients. Every person has a different learning style or characteristic for processing information. Based on differences in learning style, various instructional methods can have a role in oral health education programs.

During the treatment phase, orthodontists play an essential role in inculcating better oral hygiene practices among the patients by providing proper instructions on how to maintain good oral hygiene and creating awareness in order to prevent caries and periodontal disease. 6 There are various methods by which information can be conveyed to the patients in dentistry like verbal, printed materials, and videotapes. ${ }^{7}$ For oral hygiene to be effective, instructions given must be both remembered and understood by the patients. The instructions given by clinicians may be too technical or difficult for the patients to understand, or ambiguous. It has been recommended that educational videos should be made by the clinicians who are treating the patients so that the exact information is incorporated and conveyed to the patients. ${ }^{8}$ The use of self - educational manuals has been shown to be effective in improving oral hygiene health in dentistry. The key advantage of the video method over other instructional methods is that it can be used repeatedly as many times with no additional cost. A study was conducted on insulin dependent diabetics to teach dietary control through a specially made videotape by McCulloch et al. and they found that videotapes are better in delivering information to patients. ${ }^{9}$ The advantage of the video presentation is that it is more convenient for patients with the opportunity for self learning in privacy and comfort. 10

The objective of this study was to compare the effectiveness of audio - visual aids in contrast to verbal instructions in improving oral hygiene in orthodontic patients with moderate to poor oral hygiene.

\section{METHODS}

A prospective randomized control trial on orthodontic subjects was conducted among the out-patients of the Department of Orthodontics and Dentofacial Orthopaedics, Saveetha Dental College and Hospitals, Chennai, from September 2017 to October 2017. The sample size calculation was done based on the mean plaque score from the previous study. ${ }^{11} \mathrm{G}^{*}$ power software (version 3.0.10, Denmark) was used to determine the sample size of our study which we found to be 22 to obtain a power of $99 \%$ and maintain a type I alpha risk of 0.05 . However, we decided to take 30 patients to account for dropouts. All the patients were bonded with 0.022 - inch Mclaughlin Bennett Trevisi prescription brackets (3M Unitek Gemini series, Monrovia, Calif) by the same clinician using Ormco (Enlight ${ }^{\mathrm{TM}}$ ) orthodontic adhesive. The sample size was estimated to be 15 in each group. Subjects selected were above the age of 15 years with a full set of permanent dentitions based on their plaque index during first orthodontic visit after bonding. The inclusion criteria for this study were based on their plaque index scores (Table 1) of orthodontic patients. Patients with moderate to poor oral hygiene were included in this study. Subjects with a plaque index scores of 3 and above were selected for the study. Patients with special needs, syndromic patients, and also patients with multiple missing teeth were excluded from this study. The ethical clearance was obtained from the Institutional Ethical Committee. Before the start of the study, the patients were explained about the procedures and written informed consent was obtained.

The plaque index scoring was done on the basis of plaque adherence to the buccal surface of six teeth, upper right and left first or second premolar, upper right incisor, lower left central incisor, lower right and left first premolars. The plaque scores from second premolars were taken in patients who had their first premolars extracted as part of orthodontic treatment. The plaque scores were recorded using a periodontal probe and the scores were given based on the amount of plaque between the bracket margin and gingival margin at six sites around each bonded tooth (Table 1).

\begin{tabular}{|cc|}
\hline 0 & No Plaque \\
1 & Discontinuous band of plaque at gingival margin \\
2 & Up to $1 \mathrm{~mm}$ continuous band of plaque at gingival margin \\
3 & Band of plaque wider than $1 \mathrm{~mm}$ but less than $1 / 3$ of surface \\
4 & Plaque covering between $1 / 3$ and $2 / 3$ of surface \\
5 & Plaque covering $2 / 3$ or more of surface \\
\hline & Table 1. Plaque Index (PI) Codification \\
\hline
\end{tabular}

The selected subjects were divided into two groups using a computer - generated randomization chart. Experimental subjects $(\mathrm{N}=15)$ were given oral hygiene instructions through audio visual aids and the control group $(\mathrm{N}=15)$ were given oral hygiene instructions verbally after thorough oral prophylaxis.

Five animated videos of the brushing technique were selected from the internet for the purpose of this study which was of two minutes in duration demonstrating the tooth brushing technique and oral hygiene maintenance instructions for patients undergoing fixed orthodontic therapy. Out of five videos, one video was selected by a panel of senior orthodontists with more than ten years of experience. Group 1 subjects who were given this oral hygiene video were sent through WhatsApp.

Group 2 subjects had received verbal \& written oral hygiene information, specially designed for the study explaining the same. Instructions included details regarding how to floss their teeth and on the modified Bass brushing technique. 


\begin{tabular}{|c|c|c|c|c|c|c|}
\hline \multirow{2}{*}{ Audio Visual Group } & \multirow{2}{*}{$\begin{array}{c}\text { Mean } \\
+/ \text { - SD }\end{array}$} & \multirow{2}{*}{$\begin{array}{c}\text { Standard } \\
\text { Error }\end{array}$} & \multirow{2}{*}{$\begin{array}{c}\text { Mean } \\
\text { Difference }\end{array}$} & \multicolumn{2}{|c|}{ Confidence Interval } & \multirow{2}{*}{ Significance } \\
\hline & & & & Lower & Upper & \\
\hline Pre upper right first / second premolar & $3.73+/-0.704$ & 0.182 & \multirow{2}{*}{1.467} & \multirow{2}{*}{1.181} & \multirow{2}{*}{1.753} & \multirow{2}{*}{$0.000^{*}$} \\
\hline Post upper right first / second premolar & $2.27+/-0.594$ & 0.153 & & & & \\
\hline Pre upper right central incisor & $2.40+/-0.828$ & 0.214 & \multirow{2}{*}{0.933} & \multirow{2}{*}{0.491} & \multirow{2}{*}{1.376} & \multirow{2}{*}{$0.000^{*}$} \\
\hline Post upper right central incisor & $1.47+/-0.516$ & 0.133 & & & & \\
\hline Pre upper left first / second premolar & $3.80+/-0.775$ & 0.200 & \multirow{2}{*}{1.200} & \multirow{2}{*}{0.771} & \multirow{2}{*}{1.629} & \multirow{2}{*}{$0.000^{*}$} \\
\hline Post upper left first / second premolar & $2.60+/-0.507$ & 0.131 & & & & \\
\hline Pre lower left first / second premolar & $3.27+/-0.594$ & 0.153 & \multirow{2}{*}{1.333} & \multirow{2}{*}{0.992} & \multirow{2}{*}{1.675} & \multirow{2}{*}{$0.000^{*}$} \\
\hline Post lower left first / second premolar & $1.93+/-0.258$ & 0.067 & & & & \\
\hline Pre lower left central incisor & $2.53+/-1.060$ & 0.274 & \multirow{2}{*}{0.867} & \multirow{2}{*}{0.360} & \multirow{2}{*}{1.374} & \multirow{2}{*}{$0.003^{*}$} \\
\hline Post lower left central incisor & $1.67+/-0.488$ & 0.126 & & & & \\
\hline Pre lower right first / second premolar & $3.33+/-0.617$ & 0.159 & \multirow{2}{*}{1.467} & \multirow{2}{*}{1.055} & \multirow{2}{*}{1.878} & \multirow{2}{*}{$0.000^{*}$} \\
\hline Post lower right first / second premolar & $1.87+/-0.640$ & 0.165 & & & & \\
\hline \multicolumn{7}{|c|}{ Table 2. Paired t Test for Audio-Visual Group } \\
\hline
\end{tabular}

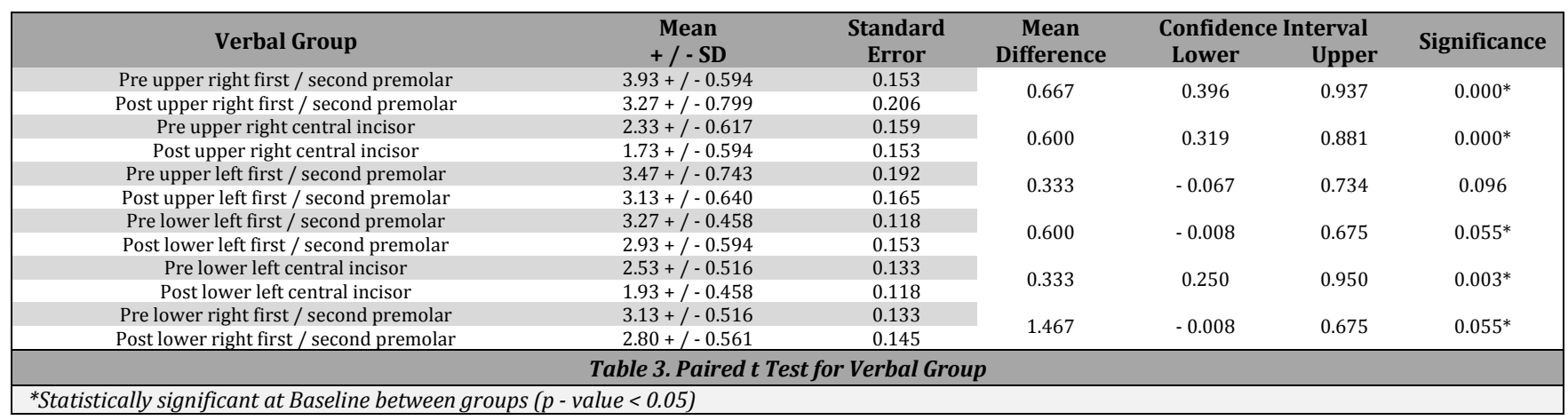

\section{Written Instructions}

\section{Brushing Technique}

- Front surfaces - Toothbrush to be held at a 45 - degree angle and brush gently using small circular motions.

- While brushing between the brackets and gums - tilt the brush toward the gum (down for the mandibular teeth, up for the maxillary teeth) and brush in circular motions.

- Chewing surfaces of teeth - firm back - and - forth motion.

- Use the mouthwash after the brushing is done.

- Spend about 10 seconds on each tooth before moving on to the next.

The changes in the plaque score were evaluated after a month. The plaque index of the same tooth which was recorded on the previous visit was repeated again to get the plaque score.

\section{Statistical Analysis}

The statistical test was done using statistical package for social sciences (SPSS) software - a parametric intragroup comparison was performed using paired ' $t$ ' test to compare the before and after plaque scores for both the groups. Independent Student ' $t$ ' test was done to assess the changes in plaque scores between both groups.

\section{RESULTS}

The results of the paired ' $\mathrm{t}$ ' test showed there was a statistically significant difference in the audio - visual group between all teeth (Table 2). Similarly, in the verbal group, there was a statistically significant difference within the groups except in 24 / 25 teeth (Table 3). An independent Student ' $\mathrm{t}$ ' test showed that there was a statistically significant difference in plaque score between audio - visual group and verbal group (Table 4) (Image 1).

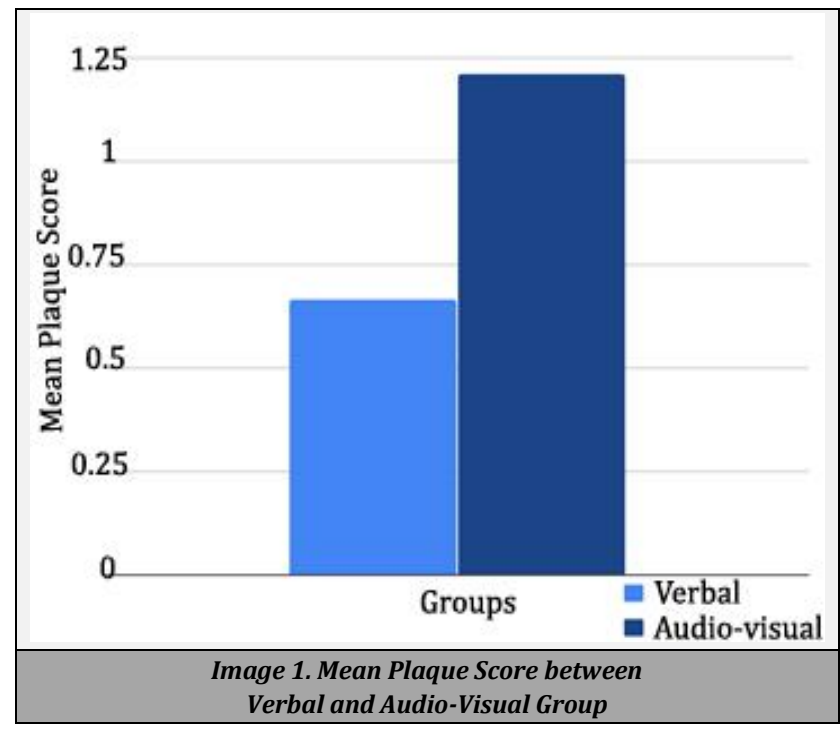

\begin{tabular}{|ccc|}
\hline Group & Mean \& SD & Significance \\
Verbal & $0.666+/-0.417$ & $0.022^{*}$ \\
\hline Audio visual & $1.211+/-0.261$ & \\
\hline Table 4. Comparison between Change in Plaque Score between \\
Verbal and Audio-Visual Group-Independent Student $t$ Test
\end{tabular}

\section{DISCUSSION}

This study compares the effectiveness of audio - visual in improving oral hygiene in orthodontic patients. The outcome variable was plaque scores measured using the modified plaque index. In our study, we have found that patients who were given instructions by means of the audio - visual method 
showed a plaque index lower than instructions given using the verbal method.

The mean plaque scores of both the verbal and audio visual groups are shown in image 2 and image 3 . The results of our study were in agreement with the previous studies were audio - visual groups showed better results than other methods.12,13 Patients usually tend to forget oral hygiene instructions given to them, so they have to be motivated frequently to maintain good oral health. With the audio - visual aids, the instructions can be repeated easily and are more understandable to patients.

There was a statistically significant difference in plaque scores in all teeth measured in the audio - visual group (Table 2). The plaque scores in the verbal group had an overall significant result except in the upper right premolar, upper central, and lower central region (Table 3). In our study, we found that between the verbal and audio - visual group there was a significant difference of 0.022 in their mean differences (Table 4).

This was contradictory to the study results done by Lees et al. where the oral hygiene of patients with fixed appliances was compared with written, verbal, and videotape oral hygiene instruction methods. ${ }^{7}$ The study results showed that there were no significant differences between the written, verbal, and videotape instruction methods. Audio - visual aids instructions seem to improve oral health with more significant results than other methods which were in agreement with our study results too. ${ }^{14}$

One more important finding that we found in our study was that the plaque scores of both groups had better improvement on the left side than the right side as this can be correlated with the patient's manual dexterity. This may be due to better manual dexterity of right handers towards the left - hand side. ${ }^{15}$

Videotapes have been used as a patient education tool for many years as its major advantage is that it has better visualization of practical techniques during small group teaching. Videos provide a sensible and easier medium for health education that is suitable for group learning as well as for individual learning. Audio visual aids offer an added advantage that the video can be repeated according to the viewer's needs. ${ }^{16,17}$ Audio - visual aids contribute to the information giving and reinforcing part of the process. Communication habits, especially between adolescents, are increasing briefly and hence audio - visual aids can deliver the message in a better way than conventional word to word instructions. ${ }^{18}$

The common method of giving oral hygiene instruction is the instruction approach on a one - to - one basis. It is time consuming and it may not be practical from a community perspective to give instructions on one to one basis. There are other methods such as leaflets, pamphlets, health messages provided to patients however through audio - visual aids the visual perception is much better, and the instructions can be reinforced again and again. ${ }^{19}$

Audio - visual aids are excellent tools for patient education, as these have a durable impression on the target population. Repeated use of audio - visual aids also contributes in reinforcing the information so that it is better retained and hence audio visual aids can briefly deliver the message in a better way than a conventional word to word instructions. ${ }^{20}$

\section{CONCLUSIONS}

In today's digital era, almost everyone owns a smartphone, with the ability to view videos and also with the advent of various apps like WhatsApp, it is very easy to pass on the message over a large scale within a matter of a few minutes with ease. Hence, audio - visual methods of instructions will be more helpful in improving oral hygiene than verbal methods.

Data sharing statement provided by the authors is available with the full text of this article at jemds.com.

Financial or other competing interests: None.

Disclosure forms provided by the authors are available with the full text of this article at jemds.com.

\section{REFERENCES}

[1] Eppright M, Shroff B, Best AM, et al. Influence of active reminders on oral hygiene compliance in orthodontic patients. Angle Orthod 2014;84(2):208-13.

[2] Mizrahi E. Enamel demineralization following orthodontic treatment. Am J Orthod 1982;82(1):62-7.

[3] Beckwith FR, Ackerman RJ Jr, Cobb CM, et al. An evaluation of factors affecting duration of orthodontic treatment. Am J Orthod Dentofacial Orthop 1999;115(4):439-47.

[4] Skidmore KJ, Brook KJ, Thomson WM, et al. Factors influencing treatment time in orthodontic patients. Am J Orthod Dentofacial Orthop 2006;129(2):230-8.

[5] Zaghrisson BU, Zachrisson S. Caries incidence and oral hygiene during orthodontic treatment. Scand J Dent Res 1971;79(6):394-401.

[6] Berlin-Broner Y, Levin L, Ashkenazi M. Awareness of orthodontists regarding oral hygiene performance during active orthodontic treatment. Eur J Paediatr Dent 2012;13(3):187-91.

[7] Lees A, Rock WP. A comparison between written, verbal and videotape oral hygiene instruction for patients with fixed appliances. J Orthod 2000;27(4):323-8.

[8] Guin JD, Donaldson R. Making your own videotapes for patient instruction. Semin Dermatol 1991;10(2):123-8.

[9] McCulloch DK, Mitchell RD, Ambler J, et al. Influence of imaginative teaching of diet on compliance and metabolic control in insulin dependent diabetes. Br Med J (Clin Res Ed) 1983;287(6408):1858-61.

[10] Dannan A. Evaluation of oral hygiene instructions awareness during orthodontic treatment among syrian orthodontists. Internet Journal of Dental Science 2008;8(1)

[11] Bowen TB, Rinchuse DJ, Zullo T, et al. The influence of text messaging on oral hygiene effectiveness. Angle Orthod 2015;85(4):543-8.

[12] Patel JH, Moles DR, Cunningham SJ. Factors affecting information retention in orthodontic patients. Am J Orthod Dentofacial Orthop 2008;133(4 Suppl):S61-7.

[13] Anderson MA, Freer TJ. An orthodontic information package designed to increase patient awareness. Aust 
Orthod J 2005;21(1):11-8.

[14] Meade CD, McKinney WP, Barnas GP. Educating patients with limited literacy skills: the effectiveness of printed and videotaped materials about colon cancer. Am J Public Health 1994;84(1):119-21.

[15] Çakur B, Yildiz M, Dane Ş, et al. The effect of right or left handedness on caries experience and oral hygiene. J Neurosci Rural Pract 2011;2(1):40-2.

[16] Shah N, Mathur V, Kathuria V, et al. Effectiveness of an educational video in improving oral health knowledge in a hospital setting. Indian J Dent 2016;7(2):70-5.

[17] Gagliano ME. A literature review on the efficacy of video in patient education. J Med Educ 1988;63(10):785-92.
[18] Zotti F, Dalessandri D, Salgarello S, et al. Usefulness of an app in improving oral hygiene compliance in adolescent orthodontic patients. Angle Orthod 2016;86(1):101-7.

[19] Krishnakumar R, Silla SS, Durai SK, et al. Comparative evaluation of audio and audio-tactile methods to improve oral hygiene status of visually impaired school children. Chrismed Journal of Health and Research 2016;3(1):55-9.

[20] Al-Silwadi FM, Gill DS, Petrie A, et al. Effect of social media in improving knowledge among patients having fixed appliance orthodontic treatment: a single-center randomized controlled trial. Am J Orthod Dentofacial Orthop 2015;148(2):231-7. 